\title{
Pemetaan Dirichlet ke Neumann untuk Rangkaian Listrik berbentuk Segi dengan Elemen bernilai Real-Positif
}

\author{
A.D. Garnadi ${ }^{1}$, M.N. Indro ${ }^{2}$, M.T Julianto ${ }^{1}$, A. Pribadi ${ }^{3}$ \\ ${ }^{1}$ Departemen Matematika, Institut Pertanian Bogor \\ ${ }^{2}$ Departemen Fisika, Institut Pertanian Bogor \\ ${ }^{3}$ STEI, Institut Teknologi Bandung
}

\begin{abstract}
Dalam tulisan ini dibahas representasi peta Dirichlet ke Neumann dari sebuah rangkaian listrik berbentuk segi dengan elemen rangkaian bernilai real positif. Permasalahan ini berasal dari analogi diskret dari Tomografi Kapasitansi. Secara tidak langsung, analogi diskret terkait dengan bentuk hampiran elemen hingga campuran dari permasalahan Tomografi Kapasitansi.
\end{abstract}

Keywords: Rangkaian Listrik, Elemen Diskret,

Plan your flight, and fly according to your plan...

(A pilot saying)

\section{Pendahuluan}

Tomografi Kapasitansi Elektrik (Electrical Capacitance Tomography (ECT)) merupakan salah satu teknologi pemetaan tak merusak yang menggambarkan distribusi bahan yang di batasi alat dengan cara melakukan pengukuran listrik di batas. Berdasarkan data pengukuran, algoritma rekonstruksi digunakan untuk mengetahui distribusi impedansi bahan dalam bentuk citra. 
serta Hukum Kirchoff di simpul :

$$
\sum_{k \in \mathcal{B}} a_{k \ell} i_{k}=0, \quad \forall \ell \in \mathcal{N} .
$$

\footnotetext{
${ }^{1}$ Istilah matriks insidensi disajikan agak berbeda dari satu buku ke buku yang lain, meski pun secara esensial identik [2][5][17], di sini kita gunakan representasi di [17], sementara di buku yang lain, transposisinya yang disebut sebagai matriks insidensi.
} 
Tuliskan :

$$
\mathbf{j}=\left[i_{1} i_{2} \cdots i_{E}\right]^{t} ; \quad \mathbf{v}=\left[v_{1} v_{2} \cdots v_{I} v_{I+1} \cdots v_{I+\beta}\right]^{t} .
$$

Dengan anggapan bahwa elektroda terakhir di bumikan, dan penomoran simpul dilakukan sedemikan rupa sehingga nomor simpulnya merupakan nomor buntut. Maka, kolom terakhir dari matriks insidensi akan dibuang [17]. Tuliskan $A$ sebagai matriks dari $A_{0}$ setelah kolom terakhirnya dibuang, tanpa kehilangan keumuman, $A$ kita sebut matriks insidensi.

Maka dari (1) dan (2) akan diperoleh sebuah sistem persamaan linear berikut :

$$
\left(\begin{array}{cc}
C & A \\
A^{t} & 0
\end{array}\right)\left(\begin{array}{l}
\mathbf{j} \\
\mathbf{v}
\end{array}\right)=\left(\begin{array}{l}
0 \\
\mathbf{q}
\end{array}\right)
$$

dengan $C=\operatorname{diag}\left(c_{1}, \cdots, c_{E}\right)$, dan $A$ matriks insidensi.

Akibat pengurutan nomor simpul dengan menomori terlebih dulu simpul di bagian dalam, kemudian mengikuti terkemudian simpul pada batas, kita peroleh partisi matriks sebagaimana berikut ini :

$$
A=\left(A_{I} \mid A_{\beta}\right) ; \quad A_{I} \in(\{-1,0,1\})^{E \times I}, A_{\beta} \in(\{-1,0,1\})^{E \times \beta},
$$

maka persamaan (3) dapat dituliskan dalam bentuk partisi :

$$
\left(\begin{array}{cc}
C & {\left[A_{I} A_{\beta}\right]} \\
{\left[\begin{array}{c}
A_{I}^{t} \\
A_{\beta}^{t}
\end{array}\right]} & 0
\end{array}\right)\left(\begin{array}{c}
\mathbf{j} \\
\mathbf{v}
\end{array}\right)=\left(\begin{array}{l}
0 \\
0 \\
\mathbf{q}
\end{array}\right),
$$

$1 \quad$ Bila input diberikan dalam bentuk arus pasangan dipol pada batas :

$$
\mathbf{q}_{\beta}= \begin{cases} \pm 1 ; j \neq k & \text { sepasang node di batas } \\ 0 & \text { lainnya. }\end{cases}
$$

Apabila dilakukan pengukuran dari batas sebanyak $m$ kali pengukuran dengan input arus pasangan dipol yang semuanya berbeda, kita peroleh sebuah persamaan matriks :

$$
K\left[a_{1} \cdots a_{m}\right]=\left[b_{1} \cdots b_{m}\right]
$$

dengan $K$ merupakan matriks sisi kiri di (4), dan kolom di ruas kanan berasal dari eksitasi arus input. 


\section{Pemetaan Tegangan ke Arus di Batas (Dirichlet to Neu- mann Map, $\Lambda_{\gamma}$ ) dari Rangkaian Bujur Sangkar (Square Network).}

Dalam bagian ini, akan ditinjau kasus khusus rangkaian kapasitor di bidang. Untuk setiap bilangan bulat positif $n$, sebuah jala kapasitor $\Omega_{h}$ dibangun dengan cara sebagai berikut. Simpul (nodes) dari $\Omega_{h}$ ialah titik kisi di bidang $p=(i, j$ ) dengan $0 \leq i \leq n+1$ dan $0 \leq j \leq n+1$, dengan tidak mengikutkan titik di sudut $(0,0),(n+1,0),(0, n+1),(n+1, n+1)$. Titik simpul dari $\Omega_{h}$ kita notasikan dengan $\Omega_{0}$. Interior dari $\Omega_{0}$, sebut $\operatorname{int}\left(\Omega_{0}\right)$, terdiri dari titik simpul $p=(i, j)$ dengan $1 \leq i \leq n$ dan $1 \leq j \leq n$. Batas dari $\Omega_{0}$, sebut $\partial \Omega_{0}$, ialah $\Omega_{0} \backslash \operatorname{int}\left(\Omega_{0}\right)$. Setiap titik interior $p$ memiliki 4 simpul tetangga, masing-masing bertempat di satu kisi terdekat di atas, kanan, bawah, dan kiri; himpunan tetangga dari simpul $p$, kita tuliskan $\mathcal{N}(p)$. Setiap simpul dalam $p, p \in \operatorname{int}\left(\Omega_{0}\right)$, memiliki sifat semua simpul tetangganya merupakan simpul dalam, $\mathcal{N}(p) \subset \operatorname{int}\left(\Omega_{0}\right)$. Setiap titik $p$ di batas, hanya tepat memiliki satu tetangga, tepatnya satu simpul dalam berada pada jarak satu kisi. Satu edge(sisi) $(p, q)$ di $\Omega$, dengan $p$ dan $q$ di int $\left(\Omega_{0}\right)$ yang berjarak satu unit kisi, atau simpul batas $p$ dengan tetangganya $q$ yang merupakan titik dalam. Himpunan edge disimbolkan dengan $\Omega_{1}$. Suatu sisi $(p, q)$ dengan $p$ titik batas dan $q$ merupakan titik dalam, disebut edge batas.

Dengan melakukan eliminasi variabel $\mathbf{j}$ di persamaan (3) kita dapatkan :

$$
A^{t} C^{-1} A \mathbf{v}=\left(\begin{array}{c}
0 \\
\mathbf{q}_{\beta}
\end{array}\right)
$$

Akibat partisi yang diinduksi oleh penomoran simpul, maka akan kita peroleh pemetaam dari tegangan ke arus di batas (Dirichlet to Neumann map) dari rangkaian listrik :[11]

$$
\mathbf{q}_{\beta}=\underbrace{\left[A_{\beta}^{t} \cdot C^{-1} \cdot A_{\beta}-A_{\beta}^{t} \cdot C^{-1} \cdot A_{I}\left(A_{I}^{t} \cdot C^{-1} \cdot A_{I}\right)^{-1} A_{I}^{t} \cdot C^{-1} \cdot A_{\beta}\right]}_{\Lambda_{\gamma}} \mathbf{v}_{\beta} .
$$

Sebaliknya pula, kita dapatkan peta input arus ke tegangan di batas ( Neumann to Dirichlet map) :

$$
\mathbf{v}_{\beta}=\Lambda_{\gamma}^{\dagger} \mathbf{q}_{\beta},
$$

dengan $[\cdot]^{\dagger}$ menyatakan invers Moore-Penrose dari [·].

Kedua peta ini mengungkapkan pada kita, bahwa tegangan pada bata selalu dapat diperoleh untuk setiap arus yang menjadi input di batas, demikian pula sebaliknya. Curtis \& Morrow [3], membahas sifat-sifat $\Lambda_{\gamma}$ untuk rangkaian bujur sangkar. 


\section{Hubungan rangkaian kapasitor dan Diskretisasi Elemen Hingga Campuran.}

Perhatikan analogi sebagaimana diperlihatkan di tabel berikut :

\begin{tabular}{|l|l|}
\hline Rangkaian Listrik & Elemen Hingga Campuran \\
\hline simpul & Elemen \\
\hline edge & edge Elemen \\
\hline
\end{tabular}

Dengan pemilihan basis elemen hingga Raviart-Thomas orde terkecil untuk approksimasi Elemen Hingga, analogi di atas akan menghasilkan struktur matriks yang serupa manakal koefisien bernilai kompleks real-positif, bandingkan dengan hasil di [9] untuk elemen bernilai positif. Sejalan dengan pemikiran di atas, akan diperoleh pula pemetaan $\Lambda_{\gamma}$ dan $\Lambda_{\gamma}^{\dagger}$ hasil diskretisasi elemen hingga yang serupa.

\section{Ucapan Terima Kasih}

Pekerjaan ini didanai oleh Kemenristekdikti melalui skim PUPT-IPB dengan kontrak nomor 079/SP2H/LT/DRPM/II/2016.

\section{References}

[1] Pribadi, A., Garnadi, A.D., Indro, M.N. and Julianto, M.T., 'Phantom Virtual'Berbasis Rangkaian Kapasitor untuk Electrical Capacitance Tomography, Prosiding Seminar ???.

[2] N.L. Biggs, Algebraic Graph Theory, Oxford University Press.

[3] E.B. Curtis \& J.A. Morrow, The Dirichlet to Neumann Map for a Kapasitor Network, SIAM J.Appl.Math., 50(1991), 1011-1029.

[4] A. R. Daniels, R. G. Green, \& Basarab-Horwath, Modelling of three dimensional resistive discontinuities using HSPICE, Meas. Sci. Tech., v 7, 338-442

[5] N. Deo, Graph Theory and its Applications, Prentice-Hall India.

[6] K. A. Dines \& R. J. Lyttle, 1981, Analysis of electrical conductivity imaging, Geophysics, v 46, 1025-1036

[7] A. D. Garnadi, 1997, Electrical Impedance Tomography Based on Mixed Finite Element Model, Proceedings CMSE97, IV.C.6-1-IV.C.6-7 
[8] A. D. Garnadi, 2004, Discrete Resistance Tomography, Proc. HPA, Yogyakarta.

[9] A. D. Garnadi, 2004, Mixed Finite Element formulation of Forward Problem of EIT on Quadrilateral, Manuscript.

[10] P. Hua \& E. J. Woo, 1990, Reconstruction Algorithms, in [18], 97-137

[11] M. A. Hussain, B. Noble, \& B. Becker, 1989, Computer simulation of an Inverse Problem for Electric Current Tomography using A Uniform Triangular Discretization, IEEE Eng. Med. Biol. Soc. 11th Ann. Int. Conf.,448-450

[12] C. Johnson, 1990, Numerical Solution of Partial Differential Equations by the Finite Element Method, Cambridge University Press

[13] W. R. B. Lionheart, S. B. Arridge, M. Scweizer, M. Vauhkonen, \& J. P. Kaipio, Electrical Impedance and Diffuse Optical Tomography Reconstruction Software, 1st World Congress in Industrial Process Tomography, Buxton, Greater Manchester, April 14-17, 1999

[14] T. Murai \& Y. Kagawa, 1985, Electrical Impedance Tomography Based on a Finite Element Model, IEEE Trans. Biomed. Eng., v BME-32, 177-184

[15] J. C. Newell, 1996, State of the art in Impedance Imaging, Lecture Notes distributed at College on medical Physics : Methods, Instrumentation and Techniques in Medical Imaging, 9-27 September 1996, ICTP, Trieste

[16] A. Plaskowski, M. S. Beck, R. Thorn, \& T. Dyakowski, 1995, Imaging Industrial Flows: Applications of electrical process, Institute of Physics Publishing

[17] G. Strang, 1986, Introduction to Applied Mathematics, Wellesley-Cambridge Press

[18] J. G. Webster (ed), 1990, Electrical Impedance Tomography, Adam Hilger

[19] T. J. Yorkey, 1990, Electrical impedance tomography with piecewise polynomial conductivities, J. Comp. Phys., 91, 344-360 